\title{
Economic burden of comorbidities in psoriasis patients in the United States: results from a retrospective U.S. database
}

\author{
Steven R. Feldman ${ }^{1}$, Haijun Tian², Isabelle Gilloteau ${ }^{3^{*}}$, Patrick Mollon ${ }^{3}$ and Meng Shu ${ }^{4}$
}

\begin{abstract}
Background: Psoriasis is a multifactorial, inflammatory, skin disease associated with various comorbidities. The cost of those comorbidities is not well characterized. The present study assesses the incremental burden of comorbidities on healthcare resource utilization, direct costs and indirect costs associated with short-term disabilities among patients with psoriasis in the United States.

Methods: A retrospective, U.S. cohort analysis was conducted using a large claims database. Adult psoriasis patients with at least two diagnoses of psoriasis during the years 2010 and 2011 (one psoriasis diagnosis had to happen in the year 2010) and with continuous enrollment of medical and pharmacy benefits in the years 2010 and 2011 were included. Psoriasis patients were categorized and compared according to the presence or absence of pre-selected comorbidities in the year 2010. Adjusted annual direct (costs associated with outpatient, emergency room, and inpatient claims, and outpatient pharmacy claims) and indirect costs (short-term disabilities) was assessed in patients with and without comorbidities using a regression analysis, controlling for age, gender, and psoriasis severity in year 2010.
\end{abstract}

Results: In total, 56,406 patients (mean [SD]) age, 51.6 [14.6] years) were included in the analysis. The most prevalent comorbidities were hypertension (34.3\%), hyperlipidemia (33.5\%), cardiovascular disease (17.7\%), diabetes (14.2\%), and psoriatic arthritis (9.9\%). Psoriasis patients with comorbidities used more healthcare resources than those without comorbidities. The incidence rate ratio (IRR) $(95 \% \mathrm{Cl})$ for patients with cardiovascular disease was $1.5(1.4-1.5)$ for outpatient visits, 2.6 (2.4 - 2.8) for hospitalizations, and $2.3(2.2-2.5)$ for ER visits, showing higher IRRs across all three types of resource use. The mean annual adjusted direct cost differences (i.e., incremental adjusted costs) in psoriasis patients with and without comorbidities were $\$ 9914.3, \$ 8386.5$, and $\$ 8275.1$ for psoriatic arthritis, peripheral vascular disease, and cardiovascular disease, respectively. The mean annual incremental adjusted indirect costs of short-term disabilities were $\$ 1333, \$ 1195, \$ 994.9$, and $\$ 996.6$ for cerebrovascular disease, obesity, peripheral vascular disease, and depression, respectively.

Conclusion: The presence of comorbidities was associated with higher healthcare resource utilization and costs among patients with psoriasis.

Keywords: Psoriasis, Costs, Comorbidities

\footnotetext{
* Correspondence: isabelle.gilloteau@novartis.com

${ }^{3}$ Novartis Pharma AG, Basel, Switzerland

Full list of author information is available at the end of the article
} 


\section{Background}

Psoriasis is a chronic, immune-mediated disease characterized by inflamed skin lesions accompanied by pain and itching [13]. In the United States (US), psoriasis affects more than $3.2 \%$ of the population or 7.4 million adults [31], with the onset most frequently occurring between 15 and 35 years of age [25, 27, 29]. Psoriasis places a substantial economic burden on both patient and society. A recent study reported the annual direct and indirect costs of psoriasis at approximately $\$ 112$ billion in 2013, which included up to $\$ 63.2$ billion of direct costs (expenses from the primary disease) and $\$ 35.4$ billion of indirect costs (determined by loss of work productivity). The cost of medical conditions associated with psoriasis was estimated at $\$ 36.4$ billion, and patients with psoriasis would pay a lifetime cost of $\$ 11,498$ for relieving physical symptoms and emotional health; however, there was limited literature around intangible cost data (willingness to pay for global well-being and alleviate sufferings from the disease) [6].

Psoriasis is also associated with multiple comorbidities including psoriatic arthritis (PsA) [15], obesity [1], hypertension [2, 15], malignancies [15], metabolic syndrome $[3,5,26]$, and cardiovascular diseases [2, 19, 28, 34]. Patients with psoriasis have an increased risk of depression/anxiety [7, 9, 23, 32] and suicidality [16, 25]. Although psoriasis is physically and psychologically devastating on its own, the presence of comorbidities increases the burden of the disease [4, 21, 22, 24, 30, 39]. Moreover, the burden of comorbidities increases with increasing psoriasis severity $[20,39]$. Psoriasis patients with comorbidities are more likely to require urgent care, have greater hospitalization rates and more frequent outpatient visits, and incur greater costs than psoriasis patients without comorbidities [21]. Comorbidities result in higher overall pharmacy, and medical costs (adjusted annual cost differences per patient $\$ 17,696$, and $\$ 5077$, respectively) [12]. In addition, in a recent study conducted in the US in psoriasis and PsA patients, 92\% of unemployed participants reported that they could not work solely due to psoriasis or PsA, revealing considerable work productivity burden of these diseases [4].

Studies assessing the economic burden associated with comorbidities in psoriasis patients remain limited. The objective of this study was to assess the incremental burden of comorbidities on healthcare resource utilization, direct costs and indirect costs associated with short-term disabilities among patients with psoriasis in the US.

\section{Methods}

\section{Data source and sample selection}

This retrospective cohort study was based on real-world data from the MarketScan ${ }^{\odot}$ Commercial and Medicare Supplemental and Coordination of Benefits databases between January 01, 2010, and December 31, 2011 and from the MarketScan Health and Productivity Management (HPM) database between January 1, 2011, and December 31, 2011.

The Commercial and Medicare supplemental Databases includes healthcare expenditures of enrolled individuals in commercial health insurance plans sponsored by more than 100 large- and medium-sized employers in the US. It informs on patients' characteristics including their comorbidity profile as well information regarding monthly enrollment data, hospitalization and outpatient medical claims, and outpatient prescription drug claims. The database is fully linkable to employees' corresponding medical and pharmacy claims data.

The MarketScan HPM Database contains workplace absenteeism, short-term disabilities, and workers' compensation data for a subset of enrollees in the Commercial Database. For short-term disabilities, data collected consist of primary reason for short-term disabilities (e.g., psoriasis), the date the episode of disability started, the date the employee returned to work (if applicable), and the payment to the disabled employee.

The study included adult patients (aged $\geq 18$ years) with at least two diagnoses of Psoriasis (International Classification of Diseases, 9th Revision, Clinical Modification [ICD-9-CM]: 696.1, 696.8) on different dates between January 01, 2010, and December 31, 2011, with at least one psoriasis diagnosis in the year 2010 to ensure patients has psoriasis in year 2010. All patients are required to have continuous enrollment of medical and pharmacy benefits in the years 2010 and 2011. As HPM data was provided at annual bases, to maximize the sample size, we used calendar year to design the study. Year 2010 data was used to define psoriasis cohort, comorbidities and baseline characteristics, and year 2011 data was used to measure healthcare utilization and costs, and indirect costs associated with short-term disabilities longitudinally. Patients covered by Health Maintenance Organization (HMO) in year 2011 were excluded from healthcare cost analysis. As for indirect costs short- term disability analysis, only subset of patients with HPM eligibility for short- term disabilities in year 2011 were included in the analysis (Fig. 1).

\section{Variables}

Age, gender, region, Charlson Comorbidity Index (CCI), and psoriasis disease severity were measured in the baseline year (i.e., year 2010). Psoriasis severity was defined according to patients' treatment type in the baseline period; patients who received at least one systemic therapy or phototherapy in the baseline period comprised patients with moderate to severe psoriasis. All other psoriasis patients were defined as mild. The comorbidities of interest selected in this analysis were based on existing published research and consisted of PsA, cardiovascular 


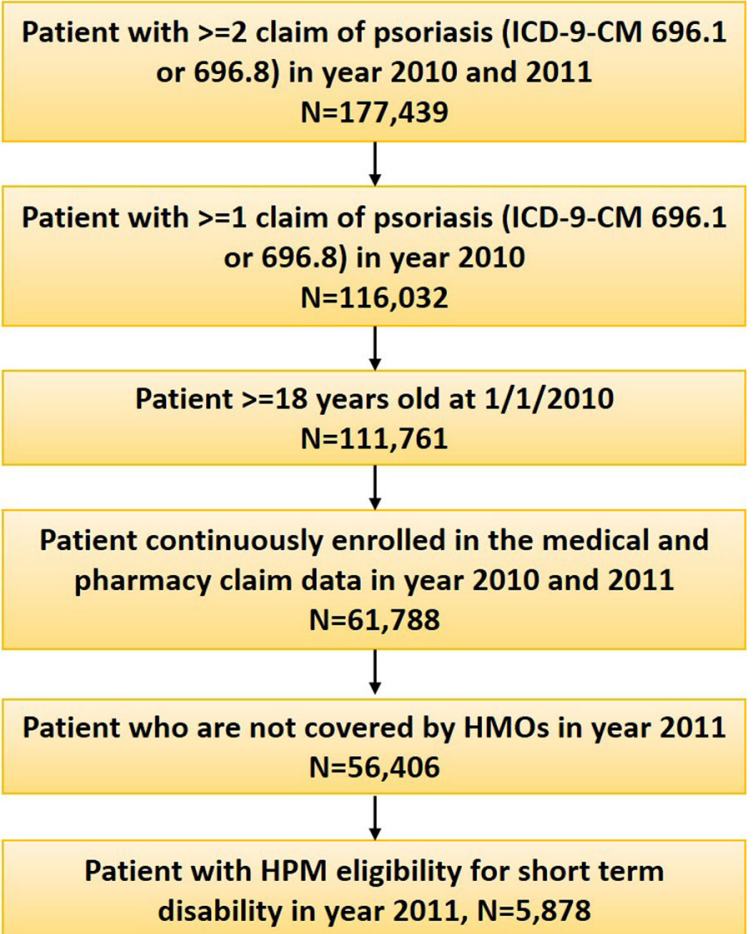

Fig. 1 Patient selection scheme. HMO: Health Maintenance Organization; HPM: Health and Productivity Management; ICD: International Classification of Diseases

disease, depression, anxiety, diabetes, hyperlipidemia, hypertension, obesity, cerebrovascular disease, and peripheral vascular disease $[3,11,14,15,17,21]$.

The direct costs were derived from the (not cause related) costs associated with outpatient, emergency room, and inpatient claims, and outpatient pharmacy claims as assessed in the year 2011. Indirect costs associated with short-term disabilities were assessed in the year 2011 using the Human Capital Approach [37]. These were estimated by multiplying number of short- term disability days, $8 \mathrm{~h}$ per day, and an average hourly wage, i.e. an average hourly wage data for all private industries from the US Bureau of Labor Statistics for the year 2011 [10].

\section{Statistical analysis}

Descriptive statistics were used for all the aforementioned variables. For continuous variables, means and standard deviations were reported; for categorical variables, counts and percentages were reported. A bivariate analysis was conducted to describe the proportion of the pre-selected comorbidities and patient characteristics by psoriasis severity in the year 2010 (moderate to severe vs. mild).

Multiple regression were performed to compare utilization and adjusted direct/indirect costs in the year 2011 between the patients with and without comorbidities, controlling for age, gender, region, and psoriasis severity in the year 2010. For health care utilization, Poisson regression models were used, and the adjusted incidence rate ratios (IRRs) with respective 95\% confidence intervals (CIs) and $p$ values were reported for patients with and without comorbidities. For direct and indirect costs associated with shortterm disabilities, two-part models (first with logistic regression for patients with positive indirect costs and second with gamma regression to model indirect positive costs) were used.

To estimate the incremental cost to comorbidities, the adjusted cost difference (change in the response by a change in a covariate) between patients with and without comorbidity was calculated using the recycled prediction method [38]. The adjusted costs for patients with each comorbidity were predicted based on the estimated two-part model by assuming all patients had such comorbidity (regardless of whether they had the comorbidity or not) while keeping other covariates constant. The adjusted costs for patients without the comorbidity were predicted using similar methodology assuming all patients had no such comorbidity. Thus, we compared two hypothetical populations (one with a comorbidity and the other without) that had the exact same values for patient characteristics in the model. The difference in adjusted costs between patients with comorbidities compared to those without comorbidities represented the incremental economic burden. The 95\% CIs were calculated using bootstrapping method for both direct and indirect costs. The analysis was performed in SAS 9.3 (SAS Institute Inc., Cary, NC).

\section{Results}

After applying the inclusion criteria, a total of 56,406 patients were included in the direct cost analysis, and 5878 in the indirect cost analysis (Fig. 1). The mean (standard deviation [SD]) age of the patients was 51.6 (14.6) years, $50 \%$ were male, and the mean CCI was 0.4 (0.9) (Table 1 ). Most patients (75.7\%) had mild psoriasis, whereas $24.3 \%$ had moderate to severe psoriasis. Hypertension (34.3\%), hyperlipidemia (33.5\%), cardiovascular disease (17.7\%), diabetes (14.2\%), and PsA (9.9\%) were the most prevalent comorbidities in the psoriasis population taken from this dataset. Patients with moderate to severe psoriasis had higher occurrence of at least one comorbidity than those with mild psoriasis $(p<0.0001)$. Comorbidities including PsA, depression, diabetes and obesity were more frequent in moderate to severe psoriasis vs. mild patients (21.2 vs. $6.2 ; p<0.0001$; (8.5 vs. $7.6 ; p=0.0005)$, (15.9 vs. $13.7 ; p<$ $0.0001)$, and (5.2 vs. $4.8 ; p=0.0687$ ), respectively (Table 1$)$.

\section{Healthcare resource utilization}

Psoriasis patients with comorbidities used more healthcare resources annually compared with those without comorbidities (IRR greater than one with $p<0.001$ for almost all comorbidities). The highest IRR (95\% CI) was 
Table 1 Patient demographics and comorbidities by severity of psoriasis

\begin{tabular}{|c|c|c|c|c|}
\hline \multirow[t]{2}{*}{ Baseline characteristics in year 2010} & Total & Moderate to severe & Mild & \multirow[t]{2}{*}{$p$ value } \\
\hline & $(N=56,406 ; 100 \%)$ & $(N=13,698 ; 24.3 \%)$ & $(N=42,708 ; 75.7 \%)$ & \\
\hline Age (years), mean (SD) & $51.63(14.59)$ & $51.79(13.95)$ & $51.58(14.79)$ & $<0.0001$ \\
\hline Male, n (\%) & $28,208(50.01)$ & $6717(49.04)$ & $21,491(50.32)$ & 0.0089 \\
\hline Female (\%) & $28,198(49.99)$ & $6981(50.96)$ & $21,217(49.68)$ & \\
\hline \multicolumn{5}{|l|}{ Region } \\
\hline North East & $10,485(18.59)$ & $2478(18.09)$ & $8007(18.75)$ & \multirow[t]{6}{*}{0.3327} \\
\hline North Central & $16,528(29.30)$ & $3988(29.11)$ & $12,540(29.36)$ & \\
\hline South & $20,633(36.58)$ & $5076(37.06)$ & $15,557(36.43)$ & \\
\hline West & $8660(15.35)$ & $2129(15.54)$ & $6531(15.29)$ & \\
\hline Missing & $100(0.18)$ & $27(0.20)$ & $73(0.17)$ & \\
\hline Charlson Comorbidity Index, mean (SD) & $0.38(0.93)$ & & & \\
\hline \multirow[t]{2}{*}{ Comorbidities, n (\%) } & Total & Moderate to severe & Mild & \multirow[t]{2}{*}{$p$ value } \\
\hline & $(n=56,406)$ & $(n=13,698 ; 24.3 \%)$ & $(n=42,708 ; 75.7 \%)$ & \\
\hline Psoriatic arthritis & $5557(9.85)$ & $2901(21.18)$ & $2656(6.22)$ & $<0.0001$ \\
\hline Cardiovascular disease & $9992(17.71)$ & $2390(17.45)$ & $7602(17.80)$ & 0.3476 \\
\hline Depression & $4388(7.78)$ & $1161(8.48)$ & $3227(7.56)$ & 0.0005 \\
\hline Anxiety & $3148(5.58)$ & $734(5.36)$ & $2414(5.65)$ & 0.1923 \\
\hline Diabetes & $8031(14.24)$ & $2181(15.92)$ & $5850(13.70)$ & $<0.0001$ \\
\hline Hyperlipidemia & $18,911(33.53)$ & $4572(33.38)$ & $14,339(33.57)$ & 0.6703 \\
\hline Hypertension & $19,365(34.33)$ & $4775(34.86)$ & $14,590(34.16)$ & 0.1350 \\
\hline Obesity & $2755(4.88)$ & $709(5.18)$ & $2046(4.79)$ & 0.0687 \\
\hline Cerebrovascular disease & $2122(3.76)$ & $462(3.37)$ & $1660(3.89)$ & 0.0059 \\
\hline Peripheral vascular disease & $2032(3.60)$ & $457(3.34)$ & $1575(3.69)$ & 0.0547 \\
\hline Any of the above comorbidities ${ }^{a}$ & $35,644(63.19)$ & $9294(67.85)$ & $26,350(61.70)$ & $<0.0001$ \\
\hline
\end{tabular}

${ }^{a}$ Any of the above comorbidities means if patients have any of the either comorbidities mentioned above. The percentages do not add up as they are not mutually exclusive

observed for cardiovascular disease for outpatient visits (1.5 [1.4 - 1.5]), hospitalizations $(2.6[2.4-2.8])$, and ER visits $(2.3[2.2-2.5])$. Psoriasis patients with any comorbidity were more likely to use healthcare resources (Table 2).

\section{Direct costs}

Table 3 presents the adjusted direct costs for patients with and without comorbidities, and incremental adjusted direct costs. In general, psoriasis patients with comorbidities had higher adjusted direct costs compared with psoriasis patients without comorbidities. Among the group of psoriasis patients with comorbidities, the annual adjusted direct costs for each comorbidity was high with higher estimates for those with PsA and peripheral vascular disease (\$25,035.9 and $\$ 24,871.7$, respectively). The highest mean incremental adjusted direct costs between the two groups of patients were observed in PsA (\$9914.3), peripheral vascular diseases (\$8386.5) and cardiovascular disease (\$8275.1) (Table 3).

\section{Indirect costs associated with short-term disabilities}

Among the group of psoriasis patients with comorbidities, the annual adjusted indirect costs for each comorbidity was particularly high for those with cerebrovascular disease and obesity (\$2501.5 and \$2293.4, respectively). Psoriasis associated with some of the comorbidities had higher adjusted indirect costs of short-term disabilities than those for patients without comorbidities. The mean incremental adjusted indirect costs for psoriasis patients with cerebrovascular disease, obesity, peripheral vascular disease, depression, and PsA were \$1333, \$1195, \$9,94.9, \$996.6, and $\$ 403.5$, respectively (Table 4 ).

\section{Discussion}

This study, using a large real-world commercial database in the US, informs on the longitudinal and annual incremental direct and indirect costs of comorbidities in psoriasis. Our results indicated that hypertension, hyperlipidemia, cardiovascular disease, diabetes, and PsA are common comorbidities in psoriasis patients. Patients 
Table 2 Adjusted incidence rate ratio for healthcare utilization in cohort of psoriasis patients with comorbidities

\begin{tabular}{|c|c|c|c|c|c|c|c|c|c|c|c|c|}
\hline Comorbidity & $\begin{array}{l}\text { Outpatient } \\
\text { visits IRR } \\
\text { Estimate } \\
\end{array}$ & $\begin{array}{l}\text { Lower } \\
\mathrm{CL}\end{array}$ & $\begin{array}{l}\text { Upper } \\
\text { CL }\end{array}$ & $p$ value & $\begin{array}{l}\text { Hospitalisation } \\
\text { visits IRR } \\
\text { Estimate }\end{array}$ & $\begin{array}{l}\text { Lower } \\
\mathrm{CL}\end{array}$ & $\begin{array}{l}\text { Upper } \\
\mathrm{CL}\end{array}$ & $p$ value & $\begin{array}{l}\text { Emergency } \\
\text { Room Visits } \\
\text { IRR Estimate } \\
\end{array}$ & $\begin{array}{l}\text { Lower } \\
\mathrm{CL}\end{array}$ & $\begin{array}{l}\text { Upper } \\
\mathrm{CL}\end{array}$ & $P$ value \\
\hline Psoriatic arthritis & 1.30 & 1.27 & 1.32 & $<0.0001$ & 1.40 & 1.27 & 1.55 & $<0.0001$ & 1.36 & 1.26 & 1.46 & $<0.0001$ \\
\hline $\begin{array}{l}\text { Cardiovascular } \\
\text { disease }\end{array}$ & 1.51 & 1.48 & 1.53 & $<0.0001$ & 2.60 & 2.41 & 2.79 & $<0.0001$ & 2.34 & 2.22 & 2.48 & $<0.0001$ \\
\hline Depression & 1.34 & 1.31 & 1.37 & $<0.0001$ & 2.05 & 1.85 & 2.26 & $<0.0001$ & 1.99 & 1.85 & 2.14 & $<0.0001$ \\
\hline Anxiety & 1.36 & 1.33 & 1.39 & $<0.0001$ & 1.82 & 1.61 & 2.05 & $<0.0001$ & 2.15 & 1.98 & 2.34 & $<0.0001$ \\
\hline Diabetes & 1.37 & 1.35 & 1.39 & $<0.0001$ & 1.93 & 1.79 & 2.08 & $<0.0001$ & 1.77 & 1.67 & 1.88 & $<0.0001$ \\
\hline Hyperlipidemia & 1.21 & 1.20 & 1.23 & $<0.0001$ & 1.09 & 1.02 & 1.16 & 0.0122 & 1.16 & 1.10 & 1.22 & $<0.0001$ \\
\hline Hypertension & 1.31 & 1.29 & 1.33 & $<0.0001$ & 1.71 & 1.60 & 1.83 & $<0.0001$ & 1.63 & 1.56 & 1.72 & $<0.0001$ \\
\hline Obesity & 1.38 & 1.35 & 1.42 & $<0.0001$ & 2.17 & 1.93 & 2.45 & $<0.0001$ & 1.89 & 1.73 & 2.08 & $<0.0001$ \\
\hline $\begin{array}{l}\text { Cerebrovascular } \\
\text { disease }\end{array}$ & 1.41 & 1.37 & 1.46 & $<0.0001$ & 2.08 & 1.84 & 2.35 & $<0.0001$ & 2.01 & 1.81 & 2.23 & $<0.0001$ \\
\hline $\begin{array}{l}\text { Peripheral } \\
\text { vascular disease }\end{array}$ & 1.47 & 1.43 & 1.52 & $<0.0001$ & 2.38 & 2.10 & 2.69 & $<0.0001$ & 1.95 & 1.75 & 2.16 & $<0.0001$ \\
\hline $\begin{array}{l}\text { Any of the above } \\
\text { comorbidities }^{\mathrm{a}}\end{array}$ & 1.49 & 1.47 & 1.51 & $<0.0001$ & 2.03 & 1.87 & 2.19 & $<0.0001$ & 1.84 & 1.75 & 1.94 & $<0.0001$ \\
\hline
\end{tabular}

Note: For each comorbidity, the reference group is the patients who do not have the respective comorbidity

IRR incidence rate ratio, $C L$ confidence limit

${ }^{a}$ Any of the above comorbidities means if patients have any of the either comorbidities mentioned above

Data for outpatient visits, hospitalization visits and emergency room visits for each of the comorbidities for the controlled variables are not reported here, but

these can be made available upon request

having moderate to severe psoriasis had higher comorbidity burden compared to those having mild disease. Moreover, presence of comorbidities among these patients is associated with an incremental economic burden compared to psoriasis patients without comorbidities.

Studies reporting incremental economic burden of comorbidities in psoriasis patients compared to those without comorbidities are very limited in the literature. Kimball et al. estimated the incremental economic burden associated with comorbidities in patients with psoriasis using data from the Ingenix Impact National Managed Care Database (IMPACT) (1999-2004) [22]. Resource utilization and costs during the 6-month follow-up period were compared for patients with comorbidity vs those without. In this study, it was reported that hyperlipidemia (27.3\%) and hypertension (25.4\%) were the most common comorbidities followed by depression (9.2\%), diabetes $(8.7 \%)$ and cardiovascular disease (8.6\%). Our study also

Table 3 Adjusted annual direct costs (\$) by type of comorbidity

\begin{tabular}{|c|c|c|c|c|c|c|c|}
\hline Comorbidity & $\begin{array}{l}\text { No. of patients } \\
\text { with comorbidity }\end{array}$ & $\begin{array}{l}\text { Adjusted costs for } \\
\text { patients with } \\
\text { comorbidity }\end{array}$ & $\begin{array}{l}\text { No. of patients } \\
\text { without } \\
\text { comorbidity }\end{array}$ & $\begin{array}{l}\text { Adjusted costs for } \\
\text { patients without } \\
\text { comorbidity }\end{array}$ & $\begin{array}{l}\text { Incremental } \\
\text { adjusted costs }\end{array}$ & Lower 95\% CL & Upper 95\% CL \\
\hline Psoriatic Arthritis & 5557 & $25,035.9$ & 50,849 & $13,376.2$ & 9914.3 & 9215.8 & $10,612.7$ \\
\hline Cardiovascular disease & 9992 & $22,287.1$ & 46,414 & $12,853.8$ & 8275.1 & 5900.6 & 7630.0 \\
\hline Depression & 4388 & $20,270.7$ & 52,018 & $14,040.2$ & 6765.3 & 1188.2 & 2081.8 \\
\hline Anxiety & 3148 & $17,569.3$ & 53,258 & $14,344.9$ & 4181.2 & 6682.3 & $10,090.7$ \\
\hline Diabetes & 8031 & $22,052.1$ & 48,375 & $13,275.2$ & 6911.4 & 6271.3 & 7551.5 \\
\hline Hyperlipidemia & 18,911 & $16,502.7$ & 37,495 & $13,527.3$ & 1635.0 & 6254.9 & 7024.3 \\
\hline Hypertension & 19,365 & $18,465.9$ & 37,041 & $12,464.5$ & 4522.3 & 5754.1 & 8255.9 \\
\hline Obesity & 2755 & $20,827.1$ & 53,651 & $14,201.2$ & 6564.5 & 5419 & 7710.1 \\
\hline Cerebrovascular disease & 2122 & $23,410.0$ & 54,284 & $14,177.5$ & 7005.0 & 2950.6 & 5411.9 \\
\hline Peripheral vascular disease & 2032 & $24,871.7$ & 54,374 & $14,138.2$ & 8386.5 & 7461.2 & 9089 \\
\hline Any of the comorbidities ${ }^{a}$ & 35,644 & $17,425.8$ & 20,762 & 9544.5 & 6639.6 & 4033.5 & 5011.2 \\
\hline
\end{tabular}

Note: The adjusted costs were predicted based on the model results using the recycled prediction method [38] for patients with and without comorbidities using the study sample. The incremental adjusted costs are differences in the adjusted costs between patients with and without comorbidities. The $95 \%$ CLs were calculated using bootstrapping method for both direct and indirect costs

${ }^{a}$ Any of the above comorbidities means if patients have any of the either comorbidities mentioned above 
Table 4 Adjusted annual indirect costs (\$) due to short-term disabilities by type of comorbidity

\begin{tabular}{|c|c|c|c|c|c|c|c|}
\hline Comorbidity & $\begin{array}{l}\text { No. of patients with } \\
\text { comorbidity }\end{array}$ & $\begin{array}{l}\text { Adjusted costs for } \\
\text { patients with } \\
\text { comorbidity }\end{array}$ & $\begin{array}{l}\text { No. of patients } \\
\text { without } \\
\text { comorbidity }\end{array}$ & $\begin{array}{l}\text { Adjusted costs for } \\
\text { patients without } \\
\text { comorbidity }\end{array}$ & $\begin{array}{l}\text { Incremental } \\
\text { adjusted costs }\end{array}$ & Lower $95 \% \mathrm{CL}$ & Upper 95\% CL \\
\hline Psoriatic arthritis & 516 & 1346.7 & 5362 & 860.0 & 403.5 & -44.9 & 852.0 \\
\hline Cardiovascular disease & 543 & 1635.0 & 5335 & 828.2 & 817.8 & 314.1 & 1321.6 \\
\hline Depression & 355 & 2112.7 & 5523 & 825.0 & 996.6 & 431.6 & 1561.6 \\
\hline Anxiety & 267 & 1344.2 & 5611 & 881.8 & 267.8 & -300.9 & 832.8 \\
\hline Diabetes & 570 & 1816.3 & 5308 & 804.7 & 928.0 & 400.1 & 1456.0 \\
\hline Hyperlipidemia & 1624 & 1163.2 & 4254 & 803.3 & 356.5 & 70.0 & 643.0 \\
\hline Hypertension & 1373 & 1319.0 & 4505 & 775.9 & 576.5 & 233.7 & 919.3 \\
\hline Obesity & 189 & 2293.4 & 5689 & 856.6 & 1195.1 & 16.1 & 2374.1 \\
\hline Cerebrovascular disease & 81 & 2501.5 & 5797 & 880.4 & 1333.1 & -181.1 & 2847.2 \\
\hline $\begin{array}{l}\text { Peripheral vascular } \\
\text { disease }\end{array}$ & 64 & 1912.2 & 5814 & 891.6 & 994.9 & -789.2 & 2779.0 \\
\hline Any of the above $e^{a}$ & 3123 & 1191.9 & 2755 & 575.0 & 614.1 & 390.0 & 838.2 \\
\hline
\end{tabular}

Note: The adjusted costs were predicted based on the model results using the recycled prediction method [38] for patients with and without comorbidities using the study sample. The incremental adjusted costs are differences in the adjusted costs between patients with and without comorbidities. The $95 \%$ CLs were calculated using bootstrapping method for both direct and indirect costs

${ }^{a}$ Any of the above comorbidities means if patients have any of the either comorbidities mentioned above

found that hyperlipidemia (33.53\%) and hypertension (34.33\%) followed by cardiovascular diseases (17.71\%), diabetes (14.24\%) and depression (7.78\%) were the most frequently reported comorbidities in psoriasis patients. Furthermore, Kimball et al. reported that patients with comorbidities were more likely to experience urgent care, greater hospitalization rates, and outpatient visits than patients without comorbidities. Similarly, our study also reported higher healthcare resource utilization burden for psoriasis patients with comorbidities vs. those without comorbidities.

Kimball et al. also reported that conditions like cerebrovascular disease, peripheral vascular disease, cardiovascular disease, and PsA are associated with the highest adjusted incremental costs in psoriasis patients among investigated comorbidities [22]. Our results corroborate these findings as PsA, cardiovascular disease, and peripheral vascular disease had the highest incremental adjusted direct costs in our study. Our study also reported substantial incremental economic burden of psychological comorbidities (depression and anxiety) among psoriasis patients, which was not previously reported in the literature. Kimbal et al. in their analysis used old data till 2004, when biologics were not available for PsO. So our study can be considered as an update after introduction of biologics to treat $\mathrm{PsO}$.

Feldman et al. reported that compared with matched psoriasis and PsA free controls, moderate-to-severe psoriasis patients with comorbid PsA had higher comorbidity and health care utilization and costs [12]. Crown et al. reported that psoriasis patients with selected comorbidities have significantly higher mean total healthcare expenditures compared to non- psoriasis persons with the same comorbidities [8]. Although there are differences between our study and those available in the literature (e.g., in terms databases used, study timelines, patient populations etc.), major findings are on similar lines.

It is known that indirect costs are associated with a high economic burden in psoriasis. Some recent U.S. studies have elucidated several components of burden of disease in psoriasis patients and a discernible proportion of economic burden is constituted by indirect costs [4, 6]. Similar reports have also been published from Germany, where average annual costs for PsA patients increased from $€ 3150$ per patient, to approximately $€ 5500-11,075$ per patient, when indirect costs are also considered [18]. Authors have also reported that indirect costs in psoriasis is a major problem in everyday life [35] and the annual indirect costs may exceed the direct costs [33]. Our study reported the incremental indirect costs due to short-term disabilities in psoriasis patients with comorbidities which have not been investigated before. Hence this finding from our study is an important addition to the existing literature.

The impact of comorbidities on health care cost may be attributable to the additional medical resources consumed for treating these illnesses. In addition, the coexistence of psoriasis and another illness may exacerbate the deleterious effects of each condition. The presence of comorbidities in patients with psoriasis may complicate the management of both diseases. Our findings can provide a more complete picture to health care providers and policy makers of the economic implications of psoriasis. These findings suggest that comorbidities deserve serious consideration, both clinically and economically, in the overall treatment and management plans for patients with psoriasis. 


\section{Limitations}

Our study is subject to several limitations. When the study was designed, our investigation was the first claims database analysis aimed at estimating the direct costs of comorbidities in psoriasis, post the introduction of biologics. However, the analysis was not adjusted by type of psoriasis treatment. The effect of treatment on the costs of comorbidities should be investigated in the future with recent datasets and patients treated with new and highly effective systemic treatments of psoriasis. Due to the observational design, the analysis may have been affected by unobserved differences between patients with comorbidities versus those without. Any coding inaccuracies may lead to misclassification, resulting in overestimation or underestimation of the number of psoriasis cases with comorbidities in the database. Psoriasis patients were categorized based on their drug therapy rather than the clinical measures of disease severity (such as Psoriasis Area and Severity Index). Drug treatment as a proxy of disease severity is commonly used in commercial claims database analyses and appears to be an acceptable method of classifying patients into disease severity categories [36]. Moreover, owing to the retrospective design of the study and missing confounding, any causal relation of comorbidities and psoriasis could not be made. The data used in this analysis was limited to patients with commercial and Medicare supplemental insurances; therefore, the findings may not be generalizable to psoriasis patient population and the population outside the US. The results were controlled with respect to age, gender, and psoriasis severity using treatment type as proxy, but other possible covariates (income, co-payment, treatment initiation, treatment type, baseline expenditures, CCI score) could also have affected the results. This research is restricted only to the economic burden associated with the presence of comorbidities and does not consider other key aspects of the burden such as humanistic or caregiver burden of the disease. Indirect costs included the value of lost work time due to short-term disabilities only and were estimated for a subset of patients for whom data were available. This warrants further investigation of the economic impact of comorbid psoriasis in terms of work productivity with consideration to absenteeism from work and long-term disabilities due to the disease.

\section{Conclusion}

Psoriasis patients with comorbidities used more healthcare resources, and had higher direct costs and indirect costs due to short- term disability compared with those without comorbidities. These findings underline the need for adequate clinical and economic considerations when treatment algorithms are devised for psoriasis patients with comorbidities. Incorporating a step for screening psoriasis patients for comorbidities may pave the way for better patient outcomes and reduced burden of disease, however blanket screening recommendations would be premature without careful analysis of the effectiveness, benefits and costs of such screening.

\section{Recommendations for future research}

The present study highlights economic burden due to presence of comorbidities in patients with psoriasis. Future research could target to assess additional indirect and intangible costs of comorbidities in psoriasis as well as effect of newly launched systemic treatments in alleviating this burden.

\section{Abbreviations}

CCl: Charlson Comorbidity Index; HMO: Health Maintenance Organization; HPM: Health and Productivity Management; ICD: International Classification of Diseases; IRR: Incidence rate ratio

\section{Acknowledgements}

The authors would like to thank Pinaki Ghosh and Niraj Modi, Novartis Healthcare Pvt. Ltd., Hyderabad, India, for providing writing/editorial assistance.

Funding

The study was funded by Novartis Pharma AG Basel, Switzerland.

Availability of data and materials

Use of the data for analyses in the present study is restricted via license agreements between study investigators and the data vendors; therefore the data are not publicly available. Use of these data sources for future research may be obtained via user-specific license agreements with the data vendors.

\section{Authors' contributions}

SRF, IG, PM and HT were involved in conception and design of the study. HT and MS carried out acquisition, analysis and interpretation of data. All authors were involved in drafting the article and revising it critically for important intellectual content. All authors approved the final version to be submitted for publication.

\section{Competing interest}

Steven R. Feldman

Steven $\mathrm{R}$. Feldman received consulting support from Novartis for this study. I have received research, speaking and/or consulting support from a variety of companies including Galderma, GSK/Stiefel, Almirall, Leo Pharma, Baxter,

Boeringer Ingelheim, Mylan, Celgene, Pfizer, Valeant, Taro, Abbvie, Cosmederm, Anacor, Astellas, Janssen, Lilly, Merck, Merz, Novartis, Regeneron, Novan, Parion, Qurient, National Biological Corporation, Caremark, Advance Medical, Suncare Research, Informa, UpToDate and National Psoriasis Foundation. I am founder and majority owner of www.DrScore.com. I am a founder and part owner of Causa Research, a company dedicated to enhancing patients' adherence to treatment.

Haijun Tian

Haijun Tian is a full-time employee of Novartis Pharmaceuticals Corporation, East Hanover, United States.

Isabelle Gilloteau

Isabelle Gilloteau is a full-time employee of Novartis Pharma AG, Basel, Switzerland.

Patrick Mollon

Patrick Mollon was an employee of Novartis Pharma AG, Basel, Switzerland while the study was conducted.

Meng Shu

Meng Shu was an employee of Beijing Novartis Pharma Co., Ltd., Beijing,

China while the study was conducted.

Consent to publish

Not applicable. 


\section{Ethics approval and consent to participate}

Consent was not needed as all patients were anonymised and only aggregate data are reported here. Ethics approval was not sought for this retrospective database study of anonymised data. The data that support the findings of this study were obtained under license from Truven Health Analytics Inc. (http://www.truvenhealth.com/your_healthcare_focus/ pharmaceutical_and_medical_device/data_databases_and_online_tools.aspx).

\section{Publisher's Note}

Springer Nature remains neutral with regard to jurisdictional claims in published maps and institutional affiliations.

\section{Author details}

'Department of Dermatology, Wake Forest University School of Medicine, 4618 Country Club Road, Winston-Salem, North Carolina, USA. ${ }^{2}$ Novartis Pharmaceuticals Corporation, East Hanover, NJ, USA. ${ }^{3}$ Novartis Pharma AG, Basel, Switzerland. ${ }^{4}$ Beijing Novartis Pharma Co. Ltd., Beijing, China.

Received: 24 November 2016 Accepted: 27 April 2017

Published online: 08 May 2017

\section{References}

1. Armstrong AW, Harskamp CT, Armstrong EJ. The association between psoriasis and obesity: a systematic review and meta-analysis of observational studies. Nutr Diabetes. 2012;2:e54.

2. Armstrong AW, Harskamp CT, Armstrong EJ. The association between psoriasis and hypertension: a systematic review and meta-analysis of observational studies. J Hypertens. 2013;31:433-42. discussion 442-3.

3. Armstrong AW, Harskamp CT, Armstrong EJ. Psoriasis and metabolic syndrome: a systematic review and meta-analysis of observational studies. J Am Acad Dermatol. 2013;68:654-62.

4. Armstrong AW, Schupp C, Wu J, Bebo B. Quality of life and work productivity impairment among psoriasis patients: findings from the National Psoriasis Foundation survey data 2003-2011. PLoS One. 2012;7:e52935.

5. Becker L, Tom WL, Eshagh K, Benjamin LT, Paller AS. Excess adiposity preceding pediatric psoriasis. JAMA Dermatol. 2014;150:573-4.

6. Brezinski EA, Dhillon JS, Armstrong AW. Economic burden of psoriasis in the United States: a systematic review. JAMA Dermatol. 2015;151:651-8.

7. Cohen BE, Martires KJ, Ho RS. Psoriasis and the risk of depression in the US population: national health and nutrition examination survey 2009-2012. JAMA Dermatol. 2016;152:73-9.

8. Crown WH, Bresnahan BW, Orsini LS, Kennedy S, Leonardi C. The burden of illness associated with psoriasis: cost of treatment with systemic therapy and phototherapy in the US. Curr Med Res Opin. 2004;20:1929-36.

9. Duffin KCMM. Identifying and managing complications and comorbidities in patients with psoriasis. Semin Cutan Med Surg. 2015;34:S30-3.

10. Employer Costs for Employee Compensation. Historical listing March 2004June 2013. 2013. Available: http://www.bls.gov/news.release/archives/ecec_ 09112013.pdf

11. Esposito M, Saraceno R, Giunta A, Maccarone M, Chimenti S. An Italian study on psoriasis and depression. Dermatology. 2006;212:123-7.

12. Feldman SR, Zhao Y, Shi L, Tran MH, Lu J. Economic and comorbidity burden among moderate-to-severe psoriasis patients with comorbid psoriatic arthritis. Arthritis Care Res (Hoboken). 2015:67:708-17.

13. Fowler JF, Duh MS, Rovba L, Buteau S, Pinheiro L, Lobo F, Sung J, Doyle JJ, Swensen A, Mallett DA, Kosicki G. The impact of psoriasis on health care costs and patient work loss. J Am Acad Dermatol. 2008:59:772-80.

14. Gottlieb AB, Chao C, Dann F. Psoriasis comorbidities. J Dermatolog Treat 2008;19:5-21.

15. Gottlieb AB, Dann F. Comorbidities in patients with psoriasis. Am J Med. 2009;122(1150):e1-9.

16. Gupta MA, Gupta AK. Depression and suicidal ideation in dermatology patients with acne, alopecia areata, atopic dermatitis and psoriasis. $\mathrm{Br}$ J Dermatol. 1998;139:846-50.

17. Herron MD, Hinckley M, Hoffman MS, Papenfuss J, Hansen CB, Callis KP, Krueger GG. Impact of obesity and smoking on psoriasis presentation and management. Arch Dermatol. 2005:141:1527-34.

18. Huscher D, Merkesdal S, Thiele K, Zeidler H, Schneider M, Zink A. Cost of illness in rheumatoid arthritis, ankylosing spondylitis, psoriatic arthritis and systemic lupus erythematosus in Germany. Ann Rheum Dis. 2006;65:1175-83.
19. Katsiki N, Anagnostis P, Athyros VG, Karagiannis A, Mikhailidis DP. Psoriasis and vascular risk: an update. Curr Pharm Des. 2014;20:6114-25.

20. Kim N, Thrash B, Menter A. Comorbidities in psoriasis patients. Semin Cutan Med Surg. 2010;29:10-5.

21. Kimball A, Wu E, Mulani P, Bao Y. Economic burden of comorbidities in patients with psoriasis. Journal of the American Academy of Dermatology, Conference: 68th Annual Meeting of the American Academy of Dermatology AAD Miami, FL United States. 2010. p. AB67.

22. Kimball AB, Guerin A, Tsaneva M, Yu AP, Wu EQ, Gupta SR, Bao Y, Mulani PM. Economic burden of comorbidities in patients with psoriasis is substantial. J Eur Acad Dermatol Venereol. 2011:25:157-63.

23. Kimball AB, Jacobson C, Weiss S, Vreeland MG, Wu Y. The psychosocial burden of psoriasis. Am J Clin Dermatol. 2005;6:383-92.

24. Kimball AB, Robinson D, Wu Y, Guzzo C, Yeilding N, Paramore C, Fraeman K, Bala M. Cardiovascular disease and risk factors among psoriasis patients in two US Healthcare databases, 2001-2002. Dermatology. 2008;217:27-37.

25. Kurd SK, Gelfand JM. The prevalence of previously diagnosed and undiagnosed psoriasis in US adults: results from NHANES 2003-2004. J Am Acad Dermatol. 2009;60:218-24.

26. Langan SM, Seminara NM, Shin DB, Troxel AB, Kimmel SE, Mehta NN, Margolis DJ, Gelfand JM. Prevalence of metabolic syndrome in patients with psoriasis: a population-based study in the United Kingdom. J Invest Dermatol. 2012;132:556-62

27. Makredes M, Robinson Jr D, Bala M, Kimball AB. The burden of autoimmune disease: a comparison of prevalence ratios in patients with psoriatic arthritis and psoriasis. J Am Acad Dermatol. 2009;61:405-10.

28. Parisi R, Rutter MK, Lunt M, Young HS, Symmons DP, Griffiths CE, Ashcroft DM, Identification \& Management of Psoriasis Associated Comorbidity Project, T. Psoriasis and the risk of major cardiovascular events: cohort study using the clinical practice research datalink. J Invest Dermatol. 2015;135:2189-97.

29. Parisi R, Symmons DP, Griffiths CE, Ashcroft DM, Identification, Management of, P. \& Associated Comorbidity Project, T. Global epidemiology of psoriasis: a systematic review of incidence and prevalence. J Invest Dermatol. 2013: 133:377-85

30. Pierard GE, Pierard-Franchimont C, Szepetiuk G, Paquet P, Quatresooz P. The therapeutic potential of TNF-alpha antagonists for skin psoriasis comorbidities. Expert Opin Biol Ther. 2010;10:1197-208.

31. Rachakonda TD, Schupp CW, Armstrong AW. Psoriasis prevalence among adults in the United States. J Am Acad Dermatol. 2014;70:512-6.

32. Russo PA, Ilchef R, Cooper AJ. Psychiatric morbidity in psoriasis: a review. Australas J Dermatol. 2004:45:155-9. quiz 160-1.

33. Schmitt JM, Ford DE. Work limitations and productivity loss are associated with health-related quality of life but not with clinical severity in patients with psoriasis. Dermatology. 2006:213:102-10.

34. Shahwan KT, Kimball AB. Psoriasis and cardiovascular disease. Med Clin North Am. 2015;99:1227-42.

35. Stern RS, Nijsten T, Feldman SR, Margolis D, Rolstad T. Psoriasis is common, carries a substantial burden even when not extensive, and is associated with widespread treatment dissatisfaction. J Investig Dermatol Symp Proc. 2004;9:136-9. Elsevier.

36. Wami WM, Buntinx F, Bartholomeeusen S, Goderis G, Mathieu C, Aerts M. Influence of chronic comorbidity and medication on the efficacy of treatment in patients with diabetes in general practice. Br J Gen Pract. 2013;63:e267-73.

37. Weisbrod B. The valuation of human-capital. J Polit Econ. 1961;69:425-36.

38. Williams R. Using the margins command to estimate and interpret adjusted predictions and marginal effects. Stata J. 2012;12:308-31.

39. Yeung H, Takeshita J, Mehta NN, Kimmel SE, Ogdie A, Margolis DJ, Shin DB, Attor R, Troxel AB, Gelfand JM. Psoriasis severity and the prevalence of major medical comorbidity: a population-based study. JAMA Dermatol. 2013:149:1173-9. 